\title{
Seizure-Induced Sympathoexcitation Is Caused by Activation of Glutamatergic Receptors in RVLM That Also Causes Proarrhythmogenic Changes Mediated by PACAP and Microglia in Rats
}

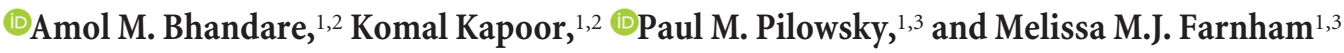 \\ ${ }^{1}$ The Heart Research Institute, Sydney 2042, New South Wales, Australia, ${ }^{2}$ Faculty of Medicine and Health Sciences, Macquarie University, Sydney 2109 , \\ New South Wales, Australia, and ${ }^{3}$ Department of Physiology, University of Sydney, Sydney 2006, New South Wales, Australia
}

Cardiovascular autonomic dysfunction in seizure is a major cause of sudden unexpected death in epilepsy. The catecholaminergic neurons in the rostral ventrolateral medulla (RVLM) maintain sympathetic vasomotor tone and blood pressure through their direct excitatory projections to the intermediolateral (IML) cell column. Glutamate, the principal excitatory neurotransmitter in brain, is increased in seizures. Pituitary adenylate cyclase activating polypeptide (PACAP) is an excitatory neuropeptide with neuroprotective properties, whereas microglia are key players in inflammatory responses in CNS. We investigated the roles of glutamate, PACAP, and microglia on RVLM catecholaminergic neurons during the cardiovascular responses to $2 \mathrm{mg} / \mathrm{kg}$ kainic acid (KA)-induced seizures in urethane anesthetized, male Sprague Dawley rats. Microinjection of the glutamate antagonist, kynurenic acid ( $50 \mathrm{nl} ; 100 \mathrm{mM})$ into RVLM, blocked the seizure-induced $43.2 \pm 12.6 \%$ sympathoexcitation $(p \leq 0.05)$, and abolished the pressor responses, tachycardia, and QT interval prolongation. PACAP or microglia antagonists (50 nl) (PACAP(6-38), $15 \mathrm{pmol}$; minocycline $10 \mathrm{mg} / \mathrm{ml})$ microinjected bilaterally into RVLM had no effect on seizure-induced sympathoexcitation, pressor responses, or tachycardia but abolished the prolongation of QT interval. The actions of PACAP or microglia on RVLM neurons do not cause sympathoexcitation, but they do elicit proarrhythmogenic changes. An immunohistochemical analysis in 2 and $10 \mathrm{mg} / \mathrm{kg}$ KA-induced seizure rats revealed that microglia surrounding catecholaminergic neurons are in a "surveillance" state with no change in the number of M2 microglia (anti-inflammatory). In conclusion, seizure-induced sympathoexcitation is caused by activation of glutamatergic receptors in RVLM that also cause proarrhythmogenic changes mediated by PACAP and microglia.

Key words: glutamate; microglia; PACAP; rat; seizure; sympathetic

Significance Statement

Sudden unexpected death in epilepsy is a major cause of death in epilepsy. Generally, seizures are accompanied by changes in brain function leading to uncontrolled nerve activity causing high blood pressure, rapid heart rate, and abnormal heart rhythm. Nevertheless, the brain chemicals causing these cardiovascular changes are unknown. Chemicals, such as glutamate and pituitary adenylate cyclase activating polypeptide, whose expression is increased after seizures, act on specific cardiovascular nuclei in the brain and influence the activity of the heart, and blood vessels. Microglia, which manage excitation in the brain, are commonly activated after seizure and produce pro- and/or anti-inflammatory factors. Hence, we aimed to determine the effects of blocking glutamate, pituitary adenylate cyclase activating polypeptide, and microglia in the RVLM and their contribution to cardiovascular autonomic dysfunction in seizure.

\section{Introduction}

Seizure-induced cardiovascular autonomic dysfunction is a common cause of sudden unexpected death in epilepsy (SUDEP), which accounts for $5 \%-17 \%$ deaths in people with epilepsy (Sakamoto et al., 2008; Surges et al., 2009; Bardai et al., 2012; Massey et al., 2014). The rostral ventrolateral medulla (RVLM) 
contains sympathetic premotor neurons $(\mathrm{C} 1)$, which are a subset of catecholaminergic neurons that express all of the enzymes necessary for the synthesis of adrenaline (Schreihofer and Guyenet, 1997; Phillips et al., 2001). Sympathetic vasomotor tone and blood pressure are regulated by $\mathrm{C} 1$ neurons, and another smaller population of neurons that is also located in the RVLM, through their direct projections to the intermediolateral (IML) cell column (Ross et al., 1984; Guyenet, 2006; Pilowsky et al., 2009). Seizure-induced increased activity of $\mathrm{C} 1$ catecholaminergic neurons (c-fos) is well documented (Kanter et al., 1995; Silveira et al., 2000). Seizure causes an increase in sympathetic nerve activity (SNA) and has significant effect on cardiac electrophysiology and heart rate (HR) (Nei et al., 2004; Metcalf et al., 2009; Damasceno et al., 2013). There is no information about the neurotransmitters mediating activation of brainstem catecholaminergic neurons contributing to the autonomic manifestations that frequently accompany epileptic seizures.

As we have documented previously, low-dose kainic acid (KA)-induced seizures in rat cause sympathoexcitation, increases in mean arterial pressure (MAP) and HR, and proarrhythmogenic changes, including prolongation of the QT interval (Bhandare et al., 2015). The evidence suggests that pituitary adenylate cyclase activating polypeptide (PACAP) and microglia have a protective effect on sympathetic preganglionic neurons in the IML cell column where they ameliorate the sympathoexcitatory effect of seizures. PACAP is well established to be neuroprotective (Shioda et al., 1998; Ohtaki et al., 2006), through its effect on microglia (Wada et al., 2013). Recently, we investigated the excitatory effect of PACAP in cardiovascular autonomic nuclei (Farnham et al., 2008, 2012). KA-induced seizures dramatically increase PACAP expression in central autonomic nuclei (paraventricular nucleus) (Nomura et al., 2000). Additionally, microglia can be pro- or anti-inflammatory in some models of diseases, such as temporal lobe epilepsy (Shapiro et al., 2008; Mirrione et al., 2010; Vinet et al., 2012). In seizure, there is extensive activation of microglia in patients and in animal models (Beach et al., 1995; Shapiro et al., 2008; Eyo et al., 2014). Moreover, there are reports suggesting that PACAP modulates the activated microglial state (Wada et al., 2013; Brifault et al., 2015). This important relationship between PACAP, microglia, and seizure-induced increase in its expression or activation in cardiovascular autonomic nuclei makes them a very promising target in the development of therapy for seizure-induced sympathoexcitation and cardiovascular dysfunction. In addition, brain glutamate levels are increased in patients and animal models of temporal lobe epilepsy (Meldrum et al., 1999; Blümcke et al., 2000) and play a major pathogenic role for neuronal hyperexcitability. However, glutamatergic drive within RVLM neurons is not important for maintenance of basal tonic activity of catecholaminergic neurons or blood pressure (Guyenet et al., 1987; Araujo et al., 1999; Sved et al., 2002). Collectively, the sympathoexcitation during seizure may be due to an increased glutamate turnover that could be reversed by glutamate antagonist microinjection into RVLM without affecting basal sympathetic output and blood pressure.

Overall, the aims of this study were to identify the role of PACAP, microglia, and glutamatergic receptors in the RVLM to regulate catecholaminergic neuronal hyperexcitability and other

The authors declare no competing financial interests.

Correspondence should be addressed to Dr. Paul M. Pilowsky, Heart Research Institute, 7 Eliza Street, Sydney 2042, NSW, Australia. E-mail: paul.pilowsky@hri.org.au.

DOI:10.1523/JNEUROSCI.2584-15.2016

Copyright $\odot 2016$ the authors $\quad 0270-6474 / 16 / 360507-12 \$ 15.00 / 0$ cardiovascular changes following low-dose KA-induced seizures in rats. To achieve these aims, we used a combination of electrophysiological and neuroanatomical approaches with KA-induced seizures in rats. Seizures were induced with $2 \mathrm{mg} / \mathrm{kg}$ intraperitoneal KA injection in urethane anesthetized, vagotomized, paralyzed, and artificially ventilated rats and $50 \mathrm{nl}$ of each PACAP antagonist, PACAP(6-38); microglia antagonist, minocycline; or glutamate antagonist, kynurenic acid (KYNA) were microinjected into the RVLM of different group of rats. The changes in microglial morphology and the expression of the anti-inflammatory M2 microglial phenotype in the vicinity of RVLM catecholaminergic neurons in response to 2 and $10 \mathrm{mg} / \mathrm{kg} \mathrm{KA}$-induced seizures in rats were analyzed with immunohistochemistry.

\section{Materials and Methods}

Animals. The animal usage and protocols were in accordance with the Australian code of practice for the care and use of animals for scientific purposes. The protocols were approved by the Animal Care and Ethics Committee of Macquarie University and the Sydney Local Health District. All electrophysiology and histology experiments were conducted on adult male Sprague-Dawley rats (250-350 g; Animal Resources Centre).

Surgical preparations. For electrophysiology experiments $(n=31)$, rats were anesthetized with $10 \%$ urethane (ethyl carbamate; $1.3-1.5 \mathrm{~g} / \mathrm{kg}$ i.p.; Sigma-Aldrich) and for histology experiments $(n=15)$ with $3 \%$ sodium pentobarbital (50 mg/kg i.p.; Virbac). The depth of anesthesia was monitored by observing reflex responses (withdrawal or pressor $>10 \mathrm{mmHg}$ ) to nociceptive stimuli (periodic tail/paw pinches). Additional anesthetic was injected $(30-40 \mathrm{mg}, 10 \%$ urethane i.v. or $1.5-2.0 \mathrm{mg}$, sodium pentobarbital i.v.), if reflex responses were observed. Atropine sulfate (100 $\mu \mathrm{g} / \mathrm{kg}$, i.p.; Pfizer) was administered with the first dose of anesthetics to prevent bronchial secretions. After the completion of the general surgical procedures described below, rats were secured in a stereotaxic frame and body temperature was recorded and maintained between $36.5^{\circ} \mathrm{C}$ and $37.5^{\circ} \mathrm{C}$ throughout the experiment using a homeothermic blanket (TC1000; CWE).

General surgical procedures and electroencephalogram (EEG) electrode placement. Procedures were performed as described previously (Bhandare et al., 2015). Briefly, the right carotid artery and jugular vein were cannulated for recording of blood pressure, and for administration of drugs and fluids, respectively, with a tracheostomy to enable mechanical ventilation. A three lead electrocardiogram (ECG; front paws, hindpaw) was recorded, and HR was derived from it. Rats were vagotomized, artificially ventilated with oxygen-enriched room air, and paralyzed with pancuronium bromide. Arterial blood gases were analyzed with an electrolyte and blood gas analyzer (IDEXX, Vetstat). $\mathrm{PaCO}_{2}$ was maintained at $40 \pm 2$ and $\mathrm{pH}$ between 7.35 and 7.45.

For the placement of EEG electrodes, burr holes were drilled bilaterally for recording over the dorsal hippocampus ( $5.2 \mathrm{~mm}$ anterior to lambda, $3 \mathrm{~mm}$ lateral to midline, and $2-3 \mathrm{~mm}$ below the skull surface), and electrode positions were confirmed with cresyl violet staining. A single 75 $\mu \mathrm{m}$ Teflon-insulated stainless steel wire (A-M Systems) was inserted into each hole using stereotaxic manipulator. The signals were amplified (CWE, BMA-931 Bioamplifier), bandpass filtered from $1 \mathrm{~Hz}$ to $10 \mathrm{kHz}$, and digitized at $20 \mathrm{kHz}$ with a $100 \times$ gain.

Seizure induction. For electrophysiology experiments, seizures were induced by intraperitoneal injection of $2 \mathrm{mg} / \mathrm{kg} \mathrm{KA}$ in Sprague Dawley rats (Bhandare et al., 2015). In the histology study, two doses of KA (2 and $10 \mathrm{mg} / \mathrm{kg}$; i.p.) were used to elicit mild and severe seizures in rats to analyze their effects on the morphology of microglia in the vicinity of catecholaminergic neurons in RVLM; $2 \mathrm{mg} / \mathrm{kg}$ is the lowest dose of KA required to induce seizure and sympathoexcitation (Bhandare et al., 2015), whereas $10 \mathrm{mg} / \mathrm{kg} \mathrm{KA}$ induces status epilepticus with generalized tonic-clonic seizures in rats (Nadler, 1981; Sperk et al., 1983). However, in our study, rats were paralyzed and had no behavioral seizures. KA responses were recorded for $2 \mathrm{~h}$ after KA injection, during which continuous monitoring of EEG was used to identify the development of sei- 
zures. To investigate the duration of seizure-induced cardiovascular responses, $2 \mathrm{mg} / \mathrm{kg}$ KA-induced seizures were recorded until cardiovascular parameters returned to baseline $(n=4)$.

In vivo electrophysiology: isolation and preparation of nerves. The left greater splanchnic sympathetic nerve at a site proximal to the celiac ganglion, and the left phrenic nerve were isolated, dissected, and tied with $5 / 0$ silk thread. Nerve activity was recorded using bipolar stainless steel electrodes. Signals were amplified (CWE, BMA-931 Bioamplifiers) (sampling rate: $6 \mathrm{kHz}$, gain: 2000, filtering: $30-3000 \mathrm{~Hz}$ ) and filtered with a $50 / 60 \mathrm{~Hz}$ line frequency filter (Humbug; Quest Scientific).

RVLM site detection, confirmation and microinjection. The dorsal surface of the medulla oblongata was exposed by occipital craniotomy and the dura was removed. The bilateral RVLM stereotaxic coordinates were measured with respect to calamus scriptorius and confirmed if a $50 \mathrm{nl}$ microinjection of $100 \mathrm{mmol} / \mathrm{L}$ glutamate increased blood pressure $>30$ $\mathrm{mmHg}$. After glutamate confirmation, stable baseline parameters were recorded for at least for $30 \mathrm{~min}$.

In vehicle and KA control groups of rats $(n=5), 50 \mathrm{nl}$ of $10 \mathrm{mmol} / \mathrm{L}$ PBS was microinjected bilaterally in the RVLM; $50 \mathrm{nl}$ of $15 \mathrm{pmol}$ of PACAP(6-38) $(150 \mu \mathrm{mol} / \mathrm{L}$ in $100 \mathrm{nl})$ (Auspep, Selleck) was microinjected bilaterally in the RVLM $(n=6)$ (Farnham et al., 2012). Minocycline $(10 \mathrm{mg} / \mathrm{ml})(n=6)$ (LeBlanc et al., 2011) and KYNA (100 mM) $(n=5)$ (Miyawaki et al., 2002) were bilaterally microinjected in the RVLM in doses of $50 \mathrm{nl}$ in different groups of rats. In all rats, microinjections were made 15 min before intraperitoneal KA or PBS injection. Microinjections were not made in $n=4$ rats that were used to investigate the duration of KA-induced cardiovascular effects. At the conclusion of the experiment, $50 \mathrm{nl}$ of Chicago Sky Blue (2\%) was microinjected at the site of the RVLM, and rats were either killed with $0.5 \mathrm{ml}$ of $3 \mathrm{M}$ potassium chloride (KCl; i.v.) or deeply anesthetized and perfused with $400 \mathrm{ml}$ of ice-cold $0.9 \%$ saline followed by $400 \mathrm{ml}$ of $4 \%$ PFA solution. The brains were removed from the perfused rats and postfixed in the same fixative overnight. Cerebrum and brainstem were sectioned coronally $(100 \mu \mathrm{m})$ and stained with cresyl violet for histological verification of the EEG electrode positions in hippocampus and microinjection site in RVLM, respectively.

Histology: perfusions. At the conclusion of the experiment, rats used for histology study (in all groups; $n=5$ ) were deeply anesthetized with an overdose of sodium pentobarbital and given $1 \mathrm{ml}$ of heparin via the venous line. Rats were transcardially perfused with $400 \mathrm{ml}$ of ice-cold $0.9 \%$ saline followed by $400 \mathrm{ml}$ of $4 \%$ PFA solution. The brains were then removed and postfixed in the same fixative for $18-24 \mathrm{~h}$.

Sectioning and immunohistochemistry. Immunohistochemical analysis was done in $n=3$ of 5 rats in each group. Brainstems were sectioned coronally (40 $\mu \mathrm{m}$ thick) with a vibrating microtome (Leica, VT1200S) and collected sequentially into five different pots containing a cryoprotectant solution and stored at $-20^{\circ} \mathrm{C}$ until further processing. Free floating sections were used for all histological procedures. Sections were rinsed, blocked, and incubated in primary antibodies: mouse antityrosine hydroxylase (TH) (1:500; Sigma-Aldrich), rabbit anti-CD206 (1:2000; Abcam), and goat anti-Iba1 (1:1000; Novus Biologicals). After $48 \mathrm{~h}$, sections were rinsed and TH, CD-206, and Ibal immunoreactivity was subsequently revealed by overnight incubation with the following secondary antibodies at 1:500 dilutions (Jackson ImmunoResearch Laboratories): Cy5-conjugated donkey anti-mouse, AlexaFluor-488conjugated donkey anti-rabbit, and Cy3-conjugated donkey anti-goat. Sections were rinsed, mounted sequentially on glass slides, and coverslipped with Vectashield (Vector Laboratories).

Data acquisition and analysis: electrophysiology data. Data were acquired using a CED 1401 ADC system (Cambridge Electronic Design) and Spike 2 acquisition and analysis software (version 8.03; Cambridge Electronic Design). The EEG activity raw data were DC removed. The power in the "gamma" frequency range $(25-45 \mathrm{~Hz})$ was analyzed, as previously shown (Olsson et al., 2006; Gurbanova et al., 2008). A power spectrum analysis was done from 5 min blocks taken 1 min before microinjection or intraperitoneal injection and 60 and $120 \mathrm{~min}$ after intraperitoneal injection. The percentage change in power spectrum area was calculated for each rat at 60 and $120 \mathrm{~min}$ after intraperitoneal injection compared with pretreatment area (taken as $100 \%$ ) and grouped together.
Phrenic nerve activity (PNA) was rectified and smoothed ( $\tau 0.5 \mathrm{~s}$ ). PNA was analyzed from 1 min blocks taken $1 \mathrm{~min}$ before microinjection and 60 and 120 min after intraperitoneal injection. The percentage change in PNA area under curve (AUC) was analyzed at 60 and $120 \mathrm{~min}$ and compared with the pretreatment area (taken as $100 \%)$. SNA was rectified,

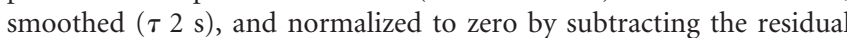
activity 5-10 min after death. The integrated SNA trace was calibrated (baseline as 100\%) and analyzed for AUC between 60 and 120 min after intraperitoneal KA or PBS injection. MAP and HR were analyzed from 1 min blocks taken 1 min before microinjection or intraperitoneal injection and 30, 60, 90, and 120 min after intraperitoneal injection (only 120 min results are shown in graphs). End-tidal $\mathrm{CO}_{2}$ and core temperature were analyzed from 1 min blocks taken $1 \mathrm{~min}$ before microinjection or intraperitoneal injection and 30, 60, 90, and 120 min after intraperitoneal injection of either KA or PBS. Arterial blood gas levels $\left(\mathrm{PaCO}_{2}\right.$ and $\left.\mathrm{pH}\right)$ were measured $10 \mathrm{~min}$ before microinjection or intraperitoneal injection and 120 min after KA or PBS injections in all animals. In the rats used to investigate the duration of KA-induced seizures, the duration of effect was analyzed from the time of intraperitoneal KA injection up to the point where SNA, MAP, and HR returned to baseline. Changes in EEG activity were analyzed at the point where SNA returned to baseline and compared against the pre-KA (control) and $60 \mathrm{~min}$ post-KA injection (seizure control) period. A log transformation was applied to EEG raw values because variances were not normally distributed, and/or heterogeneous. Statistical analysis was performed in GraphPad Prism software (version 6.05). Statistical significance was determined using one-way ANOVA followed by $t$ tests with the Holm-Šídák correction. Multiple comparisons were done between groups. $p \leq 0.05$ was considered significant.

Histology imaging and analysis. All images were acquired using a Zeiss Axio Imager Z2 (Zeiss). Images were captured at $20 \times$ and $40 \times$ magnifications. The RVLM is defined as a triangular area ventral to the nucleus ambiguus, medial to the spinal trigeminal tract, and lateral to the inferior olive or the pyramidal tracts. A $0.16 \mathrm{~mm}^{2}$ box was then placed within the imaged RVLM, and this area was used for analysis. The morphological analysis (branch length and number of endpoint processes) of Iba1labeled microglial cells in the vicinity of TH-labeled RVLM neurons was performed using ImageJ plugin software, and GraphPad Prism (version 6.05) was used for $\chi^{2}$ test for goodness of fit. The proportions of CD206labeled anti-inflammatory M2 microglia in the RVLM of 2 and $10 \mathrm{mg} / \mathrm{kg}$ KA treated rats were compared with the vehicle-treated group. The proportion of M2 microglia is equal to the number of M2 microglia divided by the total number of microglia multiplied by 100 . Statistical significance was determined using nonparametric Kruskal-Wallis test (Sokal and Rohlf, 2012).

Calculation of corrected QT (QTc) interval. QT, PR, and RR intervals were calculated from the ECG recordings. ECG raw data were processed (DC remove), wherever baseline fluctuations were prominent. QTc interval was calculated by dividing the QT interval in seconds by the square root of the R-R interval in seconds (Bazett, 1920). The QTc was obtained before and 120 min after vehicle or KA injection. The PR and QTc interval statistical analysis was performed in GraphPad Prism software (version 6.05). Statistical significance was determined using one-way ANOVA between treatment groups followed by $t$ tests with the HolmŠídák correction. Multiple comparisons were done between groups. $p \leq$ 0.05 was considered significant.

\section{Results}

Sympathoexcitation, tachycardia, and pressor responses due to KA-induced seizures in rats

Intraperitoneal injection of $2 \mathrm{mg} / \mathrm{kg} \mathrm{KA}$ induces seizures, and subsequently, increases HR, MAP, and SNA in KA control group of rats (Fig. 1A). KA (2 mg/kg i.p.) leads to development of hippocampal seizure activity within $\sim 15-20 \mathrm{~min}$. At this time, there are no changes in sympathetic activity (Fig. 2), blood pressure, or heart rate (Fig. 1A). Ten to $15 \mathrm{~min}$ after the start of the hippocampal seizure activity, SNA, MAP, and HR began to increase (Figs. $1 A, 2)$. Autonomic changes are entirely downstream effects of hippocampal seizures as there was no seizure activity (increase in 

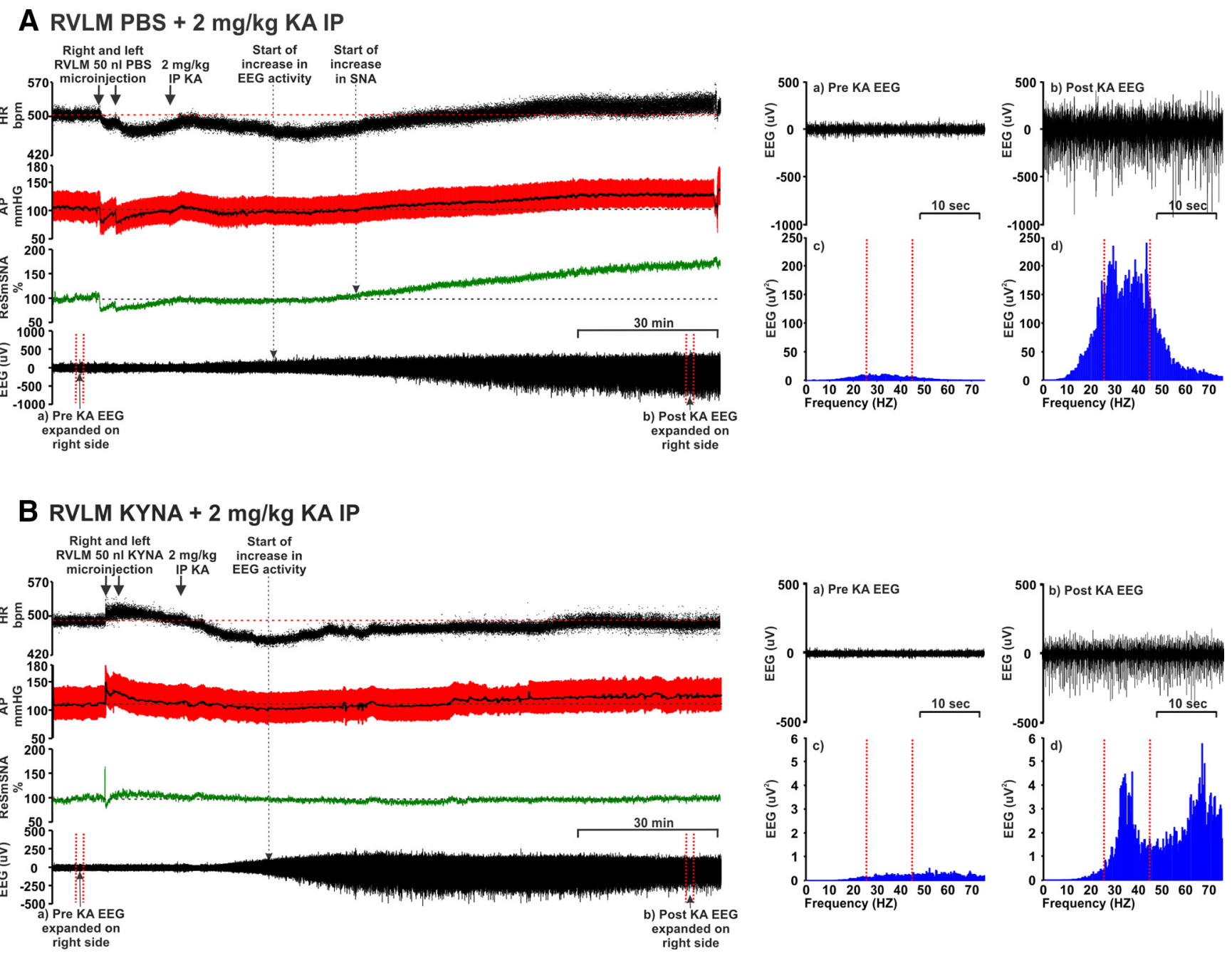

Figure 1. Effect of bilateral RVLM microinjection of (A) PBS ( $50 \mathrm{nl})$ and (B) KYNA ( $50 \mathrm{nl} ; 100 \mathrm{mM}$ ) followed by $2 \mathrm{mg} / \mathrm{kg}$ intraperitoneal KA in an anesthetized rat (see Materials and Methods) showing the effect on the following: from the top, (i) HR (bpm), (ii) AP (arterial pressure; $\mathrm{mmHg}$ ), (iii) SNA (\%), and (iv) EEG ( $\mu$ V). Arrow indicates time of RVLM microinjections and intraperitoneal KA. Dotted arrows indicate the starting points for increase in EEG and/or SNA activity. Right side panels, Pre $(\boldsymbol{a})$ and post $(\boldsymbol{b})$ KA EEG represents the expanded waveform from respective period. Baseline $(\boldsymbol{a})$, which is a pre-KA period with desynchronous waves, and $(\boldsymbol{b})$ post-KA period with increased $\gamma$ range frequencies and followed by the data from the same EEG, drawn as a power spectrum $(\boldsymbol{c}, \boldsymbol{d}$, respectively) (during post-KA period $\gamma$ range frequencies, which is shown between two dotted lines) are increased. Increase in gamma range frequency $(25-45 \mathrm{~Hz})$ is characteristic property of KA-induced seizures (0lsson et al., 2006; Gurbanova et al., 2008).

gamma frequency, which is typical sign of KA-induced seizures) in the sympathetic nerve recording until at least $70 \mathrm{~min}$ after KA injection, whereas SNA started to increase 25-30 min after KA injection (Fig. 2). Together, these findings indicate that central autonomic nuclei are not the source of KA-induced seizures. Between 60 and 120 min after KA injection, SNA AUC was increased by $43.2 \pm 12.6 \%(p=0.04)$ compared with the vehicle control group (Fig. $3 A$ ). In the KA-induced seizure group, MAP and HR were increased by $21 \pm 4 \mathrm{mmHg}(p=$ $0.008)$ and $32 \pm 7 \mathrm{bpm}(p=0.0001)$, respectively, compared with the vehicle-treated group (Fig. $3 B, C$ ): the findings support the notion that seizure is the cause of the dramatic increase in sympathetic nerve activity, tachycardia, and pressor effects (Sakamoto et al., 2008; Bealer et al., 2010). Bilateral microinjection of PBS ( $50 \mathrm{nl}$ ) had a transient and nonsignificant effect on MAP, HR, and SNA, that lasted for only a few minutes (Fig. 1A).

The induction of seizures was confirmed with hippocampal EEG recordings; the power spectra were obtained from the same expanded EEG waveforms as indicated (Fig. 1A). The spectral changes in EEG at 60 and 120 min after KA injection were obtained using Fourier analysis of 5 min EEG intervals and the AUC between gamma frequency range $(25-45 \mathrm{~Hz})$. The steep increase in $\gamma$ wave amplitude was observed at both $60(\Delta 1038 \pm 402 \%$, $p=0.0001)$ and $120 \min (\Delta 1329 \pm 390 \%, p=0.0005)$ after KA injection (Figs. $1 A, 3 D, E$ ). This finding also shows that KAinduced seizures in rats continued for at least $120 \mathrm{~min}$ following KA injection, which is consistent with results of the experiments performed to analyze the duration of seizure-induced cardiovascular effects.

KA ( $2 \mathrm{mg} / \mathrm{kg})$-induced seizures and its effects on SNA, MAP, and HR lasted for $\sim 3 \mathrm{~h}$. After this time, SNA, MAP, and HR returned to baseline values at 170, 196, and $160 \mathrm{~min}$, respectively. At these time points, EEG activity was significantly reduced compared with the seizure period (at $60 \mathrm{~min}$ after KA) but did not return to baseline.

We did not observe any changes in PNA, expired $\mathrm{CO}_{2}$, or body temperature in any of the groups (results not shown). Blood gas analysis confirmed that $\mathrm{PaCO}_{2}$ and $\mathrm{pH}$ were within normal phys- 


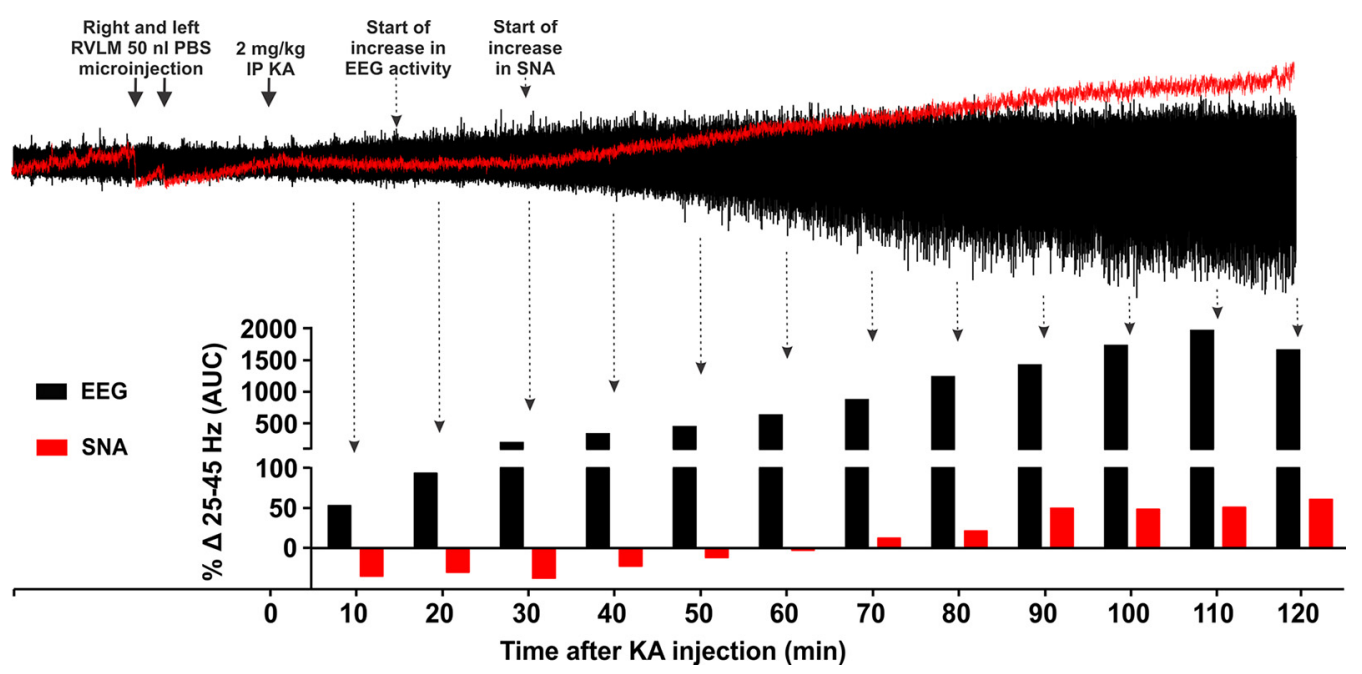

Figure 2. Effects of KA treatment on induction of seizures in hippocampus and central autonomic nuclei. Change in gamma range frequency (25-45 Hz) in hippocampal EEG and sympathetic nerve recordings every $10 \mathrm{~min}$ after $2 \mathrm{mg} / \mathrm{kg}$ KA injection. Arrow indicates time of RVLM microinjections and intraperitoneal KA. Dotted arrows indicate the starting points for increase in EEG and/or SNA activity. Induction of seizure activity in sympathetic nerve activity does not start at least until 70 min after KA injection, whereas hippocampal seizure activity starts 15-20 min after KA injection followed by an increase in SNA at 25-30 min. Time-dependent increases in hippocampal seizure activity occur up to 110 min after KA injection followed by a fall.

A
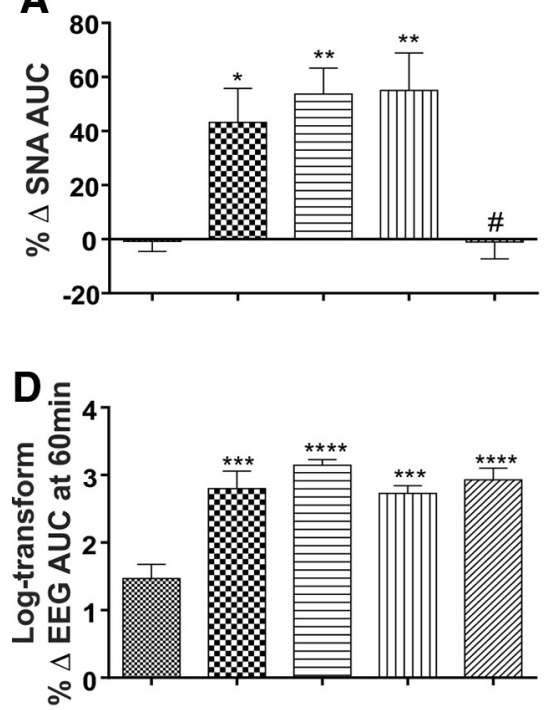

B
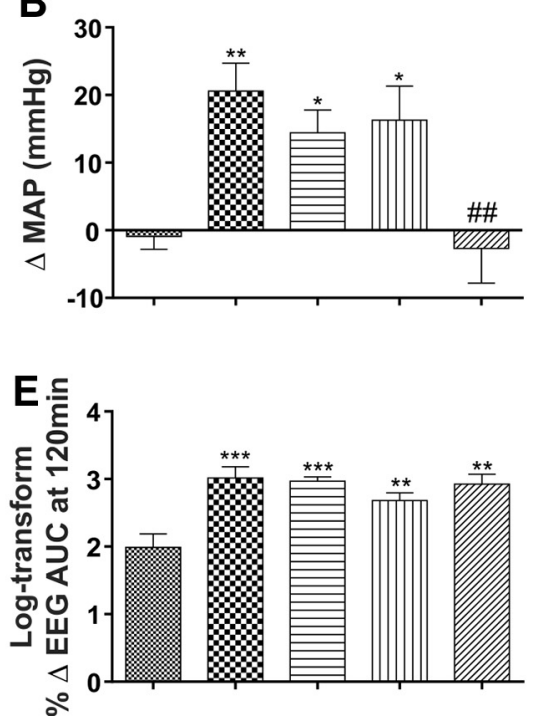

C

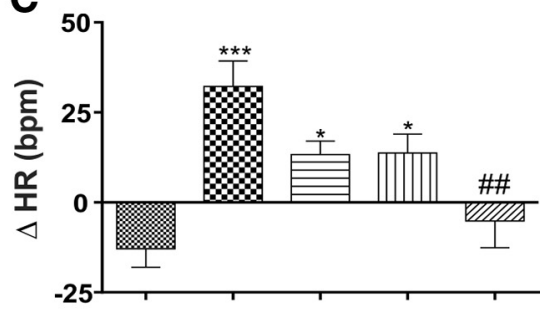

Figure 3. In vivo effects of RVLM microinjection of PBS, PACAP(6-38), minocycline, and KYNA in $2 \mathrm{mg} / \mathrm{kg}$ KA-induced seizure rats. Change in SNA (AUC) between 60 and 120 min after intraperitoneal treatment $(\boldsymbol{A})$, change in MAP 120 min after intraperitoneal PBS or KA injection $(\boldsymbol{B})$, change in HR at 120 min after intraperitoneal PBS or KA injection $(\boldsymbol{C})$, and log transform of percentage change in EEG activity (gamma wave frequency AUC), at $60 \mathrm{~min}(\boldsymbol{D})$ and $120 \mathrm{~min}(\boldsymbol{E})$ after intraperitoneal PBS or KA injection in different groups of rats after development of seizure. Statistical significance was determined using one-way ANOVA followed by $t$ tests with a Holm-Š́dák correction. Data are mean \pm SEM. ${ }^{* * * *} p \leq 0.0001$ compared with vehicle control group. ${ }^{* * *} p \leq 0.001$ compared with vehicle control group. ${ }^{* *} p \leq 0.01$ compared with vehicle control group. ${ }^{*} p \leq 0.05$ compared with vehicle control group. ${ }^{\#} p \leq 0.05$ compared with KA control group. ${ }^{\# \#} p \leq 0.01$.

iological range $\left(\mathrm{PaCO}_{2}\right.$ was $40 \pm 2$ and $\mathrm{pH}$ between 7.35 and 7.45) throughout the experiment.

Sympathoexcitation, tachycardia, and pressor effects during seizure are caused by glutamatergic receptors in the RVLM and not by PACAP or microglial activation

Our findings demonstrate that sympathoexcitation during seizure is caused by glutamatergic receptor activation in the RVLM because bilateral microinjection of glutamate antagonist KYNA completely abolished the seizure-induced sympathoexcitation in rats (Figs. $1 B, 3 A$ ). After microinjection of KYNA in five rats, KA-induced seizures were present (Figs. $1 B, 3 D, E$ ), but pressor and heart rate responses were blocked $(p=0.005$ and $p=0.001$, respectively) compared with KA control group (Figs. $1 B, 3 B, C$ ). The KA-induced seizures caused no change $(\Delta-1.0 \pm 6.2 \%)$ in SNA after bilateral microinjection of KYNA and was significantly reduced compared with KA control group $(p=0.04)$. In these groups of rats, MAP and HR were not significantly changed compared with the vehicle-treated group $(\Delta-3 \pm 5 \mathrm{mmHg}$ and $\Delta-5 \pm 7 \mathrm{bpm}$, respectively; Fig. $3 B, C)$. The findings reveal that KA-induced sympathoexcitation, tachycardia, pressor responses along with changes in QT interval are downstream effects of seizure and do not have a direct effect on cardiomyocytes.

Bilateral microinjection of PACAP(6-38) into the RVLM of KA-induced seizure rats did not ameliorate the significant in- 

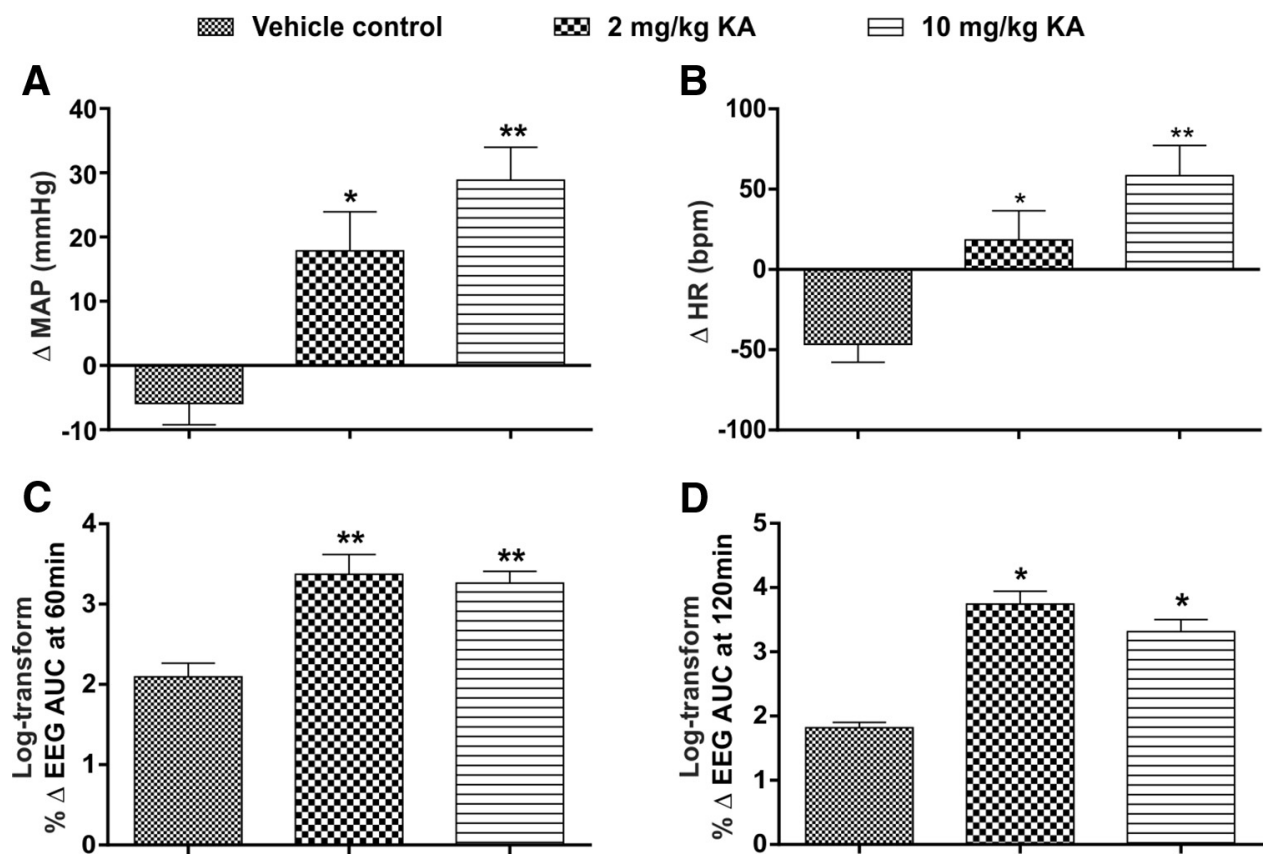

Figure 4. In vivo effects of PBS and KA-induced (2 and $10 \mathrm{mg} / \mathrm{kg}$ ) seizures in rats studied for histology. Change in MAP $(A)$ and HR ( $B$ ), at 120 min after intraperitoneal PBS or KA (2 and $10 \mathrm{mg} / \mathrm{kg})$ injection and percentage change in EEG activity (gamma wave frequency AUC), at $60 \mathrm{~min}(\boldsymbol{C})$ and $120 \mathrm{~min}$ (D) after intraperitoneal PBS or KA (2 and $10 \mathrm{mg} / \mathrm{kg})$ injection in different groups of rats. In all groups, $n=5$. Statistical significance was determined using one-way ANOVA followed by $t$ tests with a Holm-Šídák correction. Data are mean \pm SEM. ${ }^{* *} p \leq 0.01$ compared with vehicle control group. ${ }^{*} p \leq 0.05$ compared with vehicle control group.

crease in SNA $(\Delta 53.7 \pm 9.6 \% ; p=0.007)$ compared with the vehicle-treated group (Fig. $3 A$ ). The HR and MAP responses in $\mathrm{PACAP}(6-38)$ group were still significantly increased compared with the vehicle control group of rats (Fig. $3 B, C$ ). The lack of response to the PACAP antagonist $(\operatorname{PACAP}(6-38))$ was replicated following bilateral RVLM microinjection of minocycline in seizure-induced rats. Following minocycline, there was a significant increase in SNA $(\Delta 55.1 \pm 13.8 \% ; p=0.006$; Fig. $3 A)$, as well as MAP and $\operatorname{HR}(\Delta 16 \pm 5 \mathrm{mmHg}$ and $\Delta 14 \pm 5 \mathrm{bpm} ; p=0.04$ and $p=0.02$, respectively; Fig. $3 B, C)$ compared with vehicle control group of rats.

\section{After KA induced seizures, microglia are in surveillance state in the vicinity of the RVLM neurons with no change in the proportion of M2 phenotype}

Immunohistochemical analysis was done in rats with vehicle treatment and 2 and $10 \mathrm{mg} / \mathrm{kg}$ intraperitoneal KA $(n=3)$ to analyze the morphology of Iba1-labeled microglia and proportion of anti-inflammatory M2 phenotype in the vicinity of THlabeled RVLM neurons. The effect of different doses of KA on MAP, HR, and EEG are shown in Figure $4(n=5)$. At $120 \mathrm{~min}$ after 2 and $10 \mathrm{mg} / \mathrm{kg}$ KA treatment, the MAP $(\Delta 18 \pm 6$ and $\Delta$ $29 \pm 5 ; p=0.02$ and 0.001 , respectively; Fig. $4 A), \operatorname{HR}(\Delta 18 \pm 18$ and $\Delta 58 \pm 19 ; p=0.05$, and 0.002 , respectively; Fig. $4 B)$, EEG activity at $60 \min (\Delta 1791 \pm 622$ and $\Delta 1651 \pm 400 ; p=0.007$ and 0.007 ; respectively; Fig. $4 C)$, and EEG activity at $120 \mathrm{~min}(\Delta$ $4164 \pm 2504$ and $\Delta 1995 \pm 563 ; p=0.04$ and 0.04 ; respectively; Fig. 4D) were significantly increased compared with vehicletreated rats. The findings are consistent with in vivo electrophysiology data and our previous studies. Immunohistochemical analysis revealed that TH-immunoreactive (ir) neurons were surrounded with typical resting microglial cells in all three groups (Fig. 5A-C). In all three groups, microglia appeared with a round cell body and processes that appeared normal with few ramifications (Fig. $5 A-C$ ). The total number of microglia in each group are shown in Figure 5D. A branch length, and number of endpoint analysis, was performed to identify the activated microglia. There were no differences in mean branch length, and number of endpoint processes of Ibal-labeled microglia between vehicle control and seizure-induced rats (Fig. 5E,F). The proportion of anti-inflammatory M2 phenotype of microglia was $14.2 \pm 1.4 \%$ in saline-treated rats, which was similar in 2 and $10 \mathrm{mg} / \mathrm{kg} \mathrm{KA-}$ treated rats $(10.1 \pm 2.5 \%$ and $9.6 \pm 2.4 \%$, respectively; Fig. $5 G)$. The findings revealed that microglia are in a surveillance state with no differences in their morphology and proportion of M2 phenotype, at least in the RVLM, between vehicle and seizure-induced groups. These results are consistent with our electrophysiology findings where microinjection of a microglia antagonist had no effect on increase in SNA, MAP, and HR in KA-induced seizure rats.

Proarrhythmogenic ECG changes during seizures are driven by activation of glutamatergic receptors, PACAP, and microglia

The $2 \mathrm{mg} / \mathrm{kg}$ KA-induced seizures caused prolongation of QT interval. The $\Delta \mathrm{QTC}$ was significantly increased in KA control group $(\Delta 8.2 \pm 2.5 \mathrm{~ms} ; p=0.02)$ compared with vehicle treatment (Fig. 6A). These changes in QT interval are most clearly seen in Poincare plots before and after treatment; representative QT Poincare plots from each group are shown in Fig. 7A. KA control group showed almost complete dispersion of the QT interval along with arrhythmic behavior in heart rate (multiple ellipses) (Fig. 7AII). Despite this, there was no evidence of atrial fibrillation, although there was evidence of dramatic decrease in PR interval after KA treatment (Figs. 6B, 7BII). The prolongation of QT interval ( $\triangle \mathrm{QT}$ c) was completely blocked by administration of glutamate receptors antagonist KYNA in the RVLM $(p=0.02$; Figs. $6 A, 7 A V)$; nevertheless, bilateral microinjection of KYNA has no effect on seizure-induced shortened PR interval (Figs. $6 B$, $7 B V)$. PACAP $(6-38)$ and minocycline microinjections also 


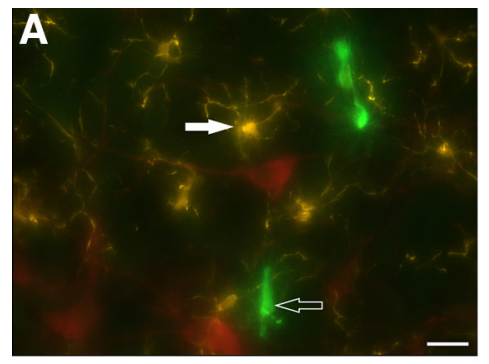

D
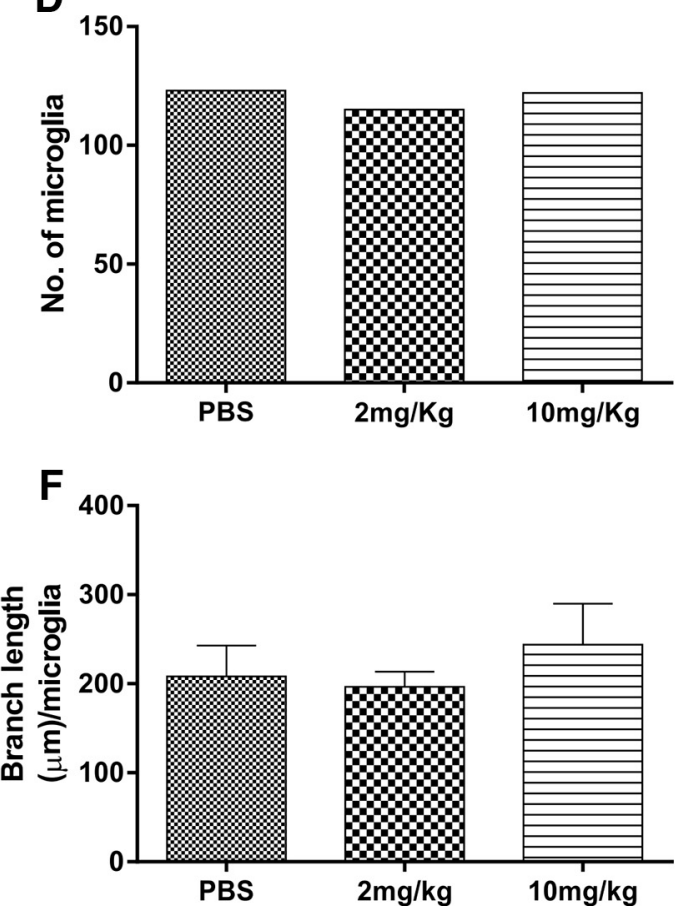
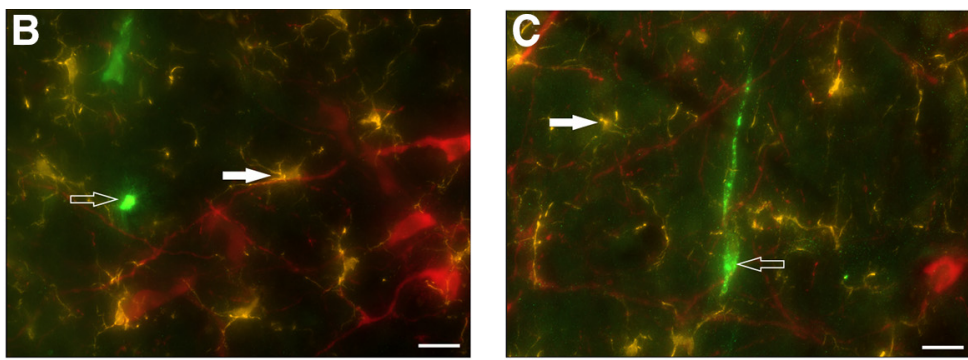

E

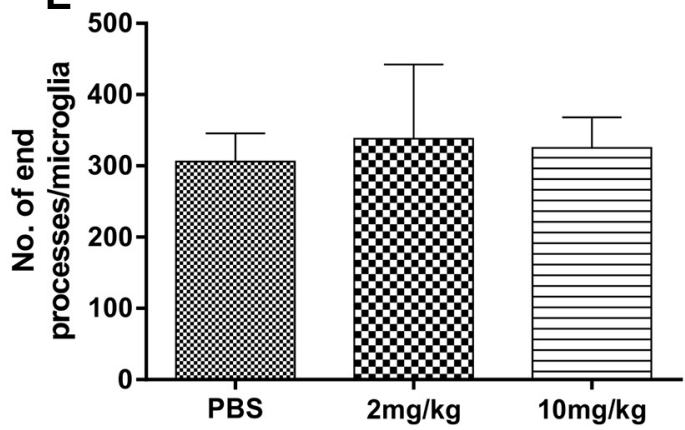

G

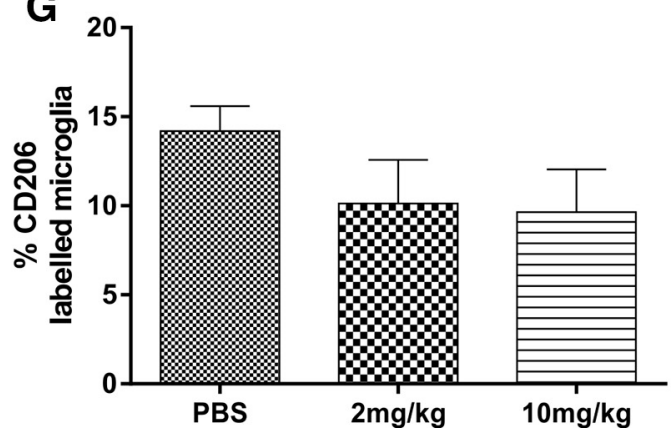

Figure 5. Fluorescence images of RVLM area containing $\mathrm{TH}^{+}{ }^{+}$-ir (red), Iba1-labeled microglia (yellow), and CD206-labeled M2 microglial cells (green) and their morphological analysis in different treatment groups of rats. Scale bar, $20 \mu \mathrm{m}$. TH, Iba1 and CD206 immunoreactivity in RVLM in PBS (A), $2 \mathrm{mg} / \mathrm{kg} \mathrm{KA}(\boldsymbol{B})$, and $10 \mathrm{mg} / \mathrm{kg} \mathrm{KA}(\boldsymbol{C})$ treated rats. In all of these three groups, TH ${ }^{+}$-ir neurons (red) were surrounded with microglia with its round cell body and normal appearing processes with few ramifications (closed arrow) and no change in number of anti-inflammatory $\mathrm{M} 2 \mathrm{microglia}$ (open arrow). Quantitative analysis of number of microglial cells in mean square area $(\boldsymbol{D})$, number of end processes/microglia $(\boldsymbol{E})$, branch length $(\boldsymbol{\mu m}) /$ microglia of $\mathrm{Iba1-labeled} \mathrm{microglial} \mathrm{cells}(\boldsymbol{F})$, and percentage of CD206-labeled M2 microglial cells (G) in the RVLM of vehicle-treated and KA-induced seizure ( 2 and $10 \mathrm{mg} / \mathrm{kg}$ i.p.) rats.

A

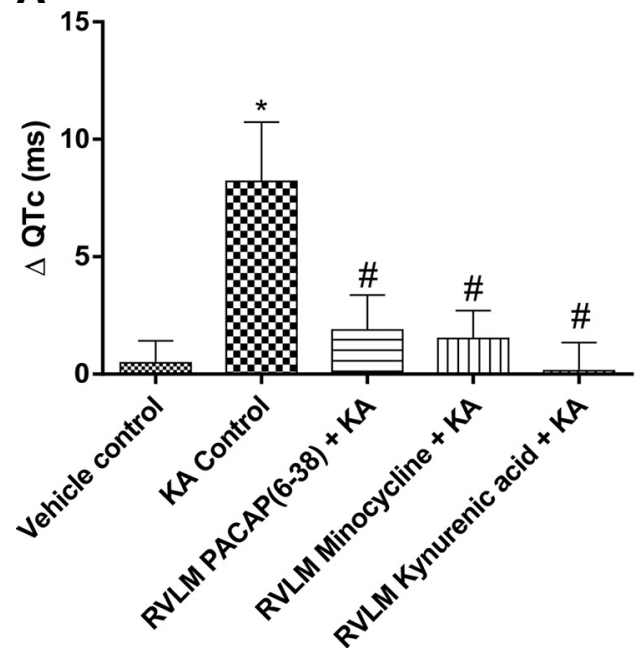

B

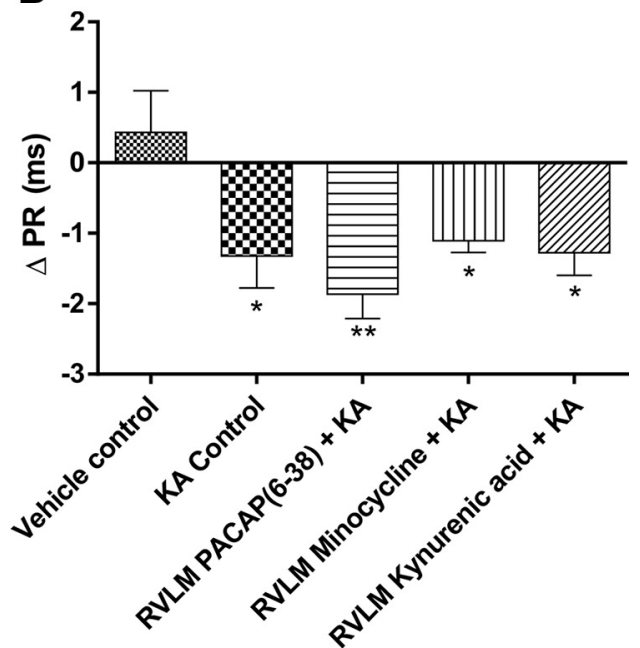

Figure 6. Proarrhythmogenic effects of seizures. Group data showing changes in QTc interval ( $\boldsymbol{A}$ ) and PR interval $(\boldsymbol{B}) 120$ min after intraperitoneal injection of PBS or KA in different groups of rats. Statistical significance was determined using one-way ANOVA followed by $t$ tests with a Holm-Šídák correction. Data are mean $\pm S E M .{ }^{* *} p \leq 0.01$ compared with vehicle control group. ${ }^{*} p \leq 0.05$ compared with vehicle control group. ${ }^{\#} p \leq 0.05$ compared with KA control group. 

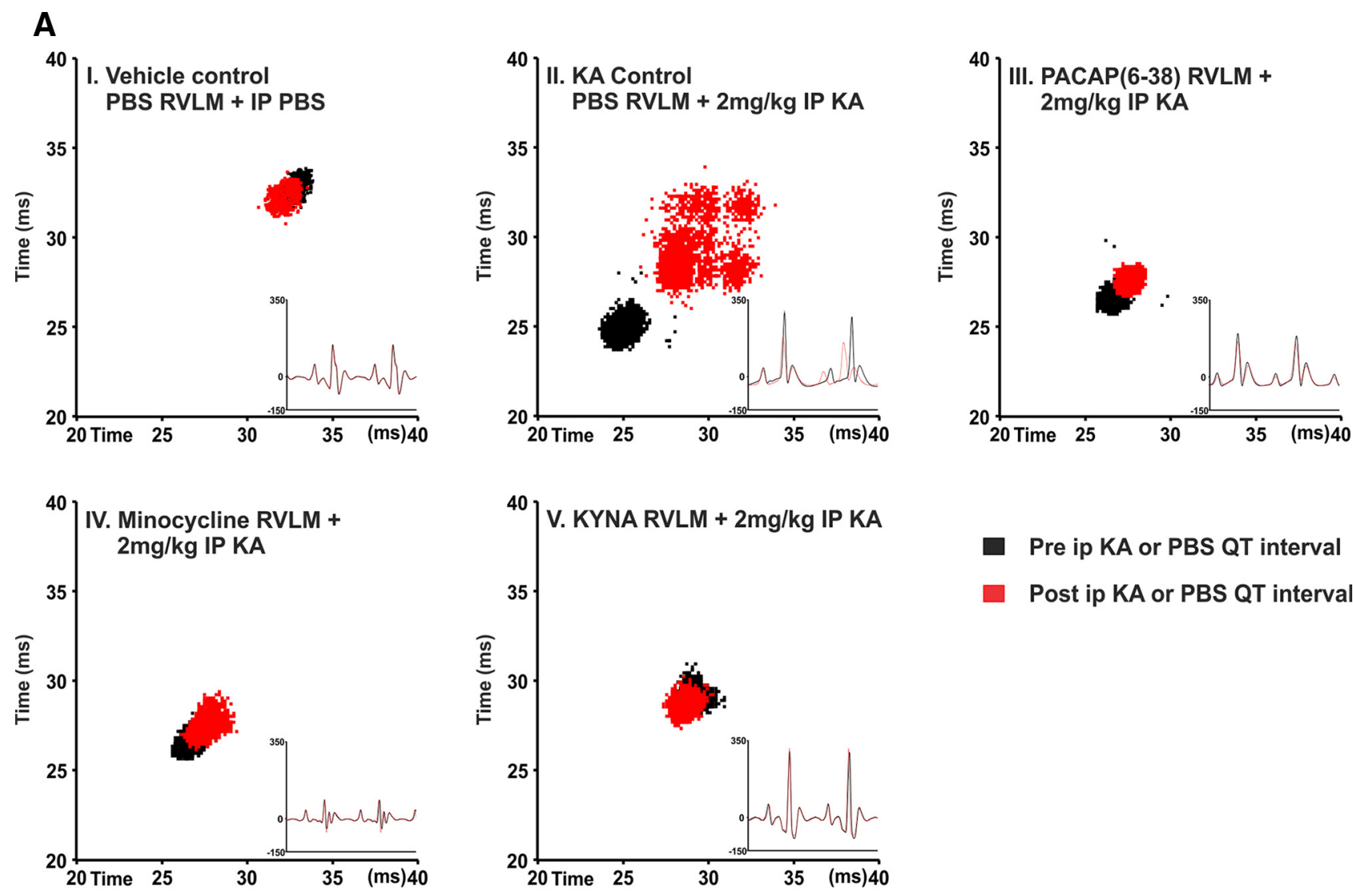

Pre ip KA or PBS QT interval
$\square$ Post ip KA or PBS QT interval
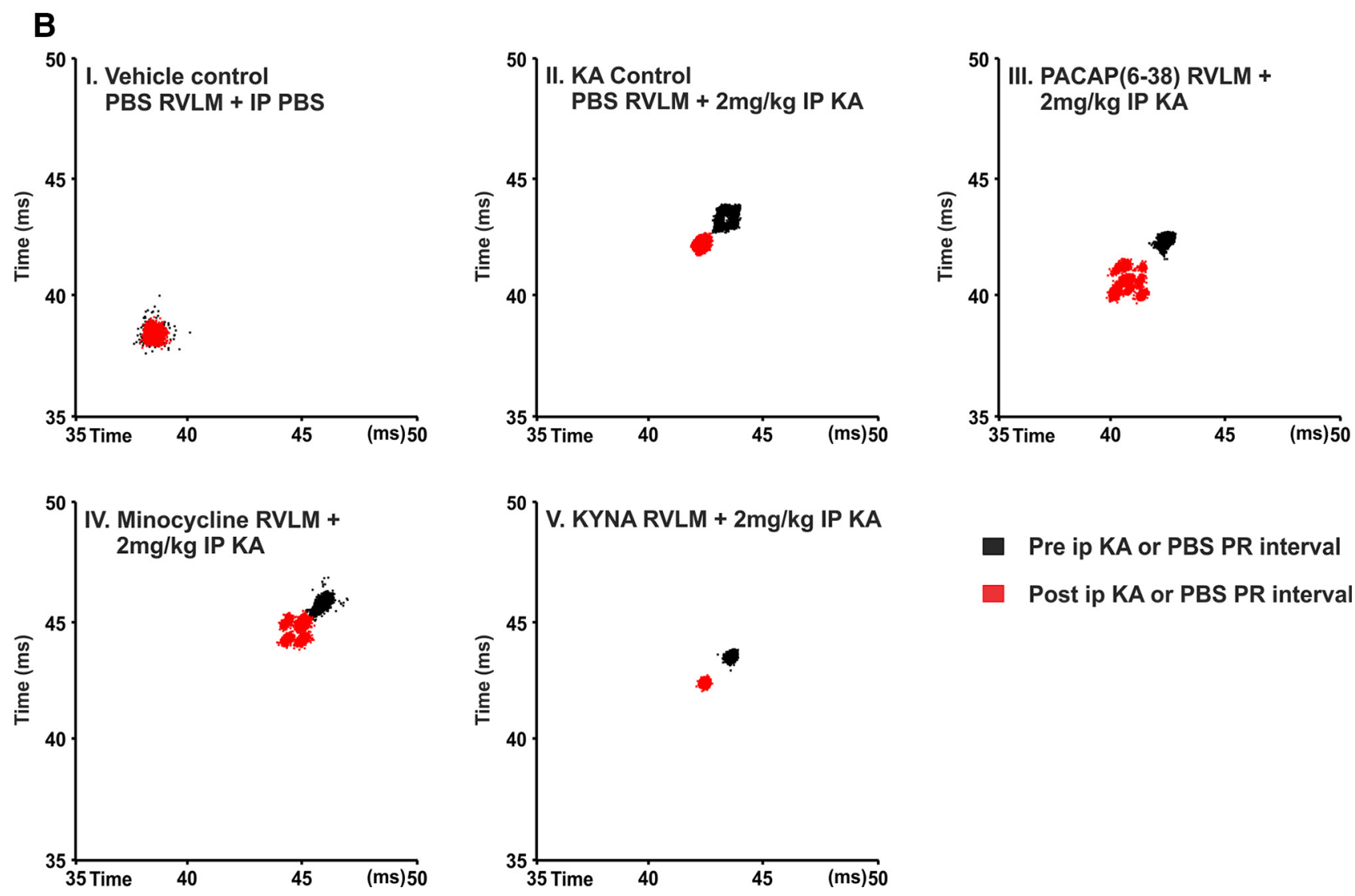

Pre ip KA or PBS PR interval

Post ip KA or PBS PR interval

Figure 7. Representative Poincare plots illustrate the changes in QT interval $(\boldsymbol{A})$ and PR interval ( $\boldsymbol{B})$ following KA-induced seizures in rats. $\boldsymbol{A}$, Treatment with KA causes a dramatic dispersion in the QT interval (prolongation) and arrhythmic behavior in the heart rate (multiple ellipses) (II). In rats treated with the PACAP antagonist (PACAP(6-38)) or (Figure legend continues.) 
significantly reduced $\Delta$ QTc interval compared with KA control group of rats $(\Delta 1.9 \pm 1.5 ; p=0.03$ and $\Delta 1.5 \pm 1.2 ; p=0.03$; Fig. $6 A)$. In PACAP (6-38) and minocycline-treated groups, prolongation of QT interval and dysrhythmia is abolished. As shown in Figure 7A, PACAP(6-38) and minocycline treatment in KAinduced seizure rats has almost similar patterns of pre- and post-QT interval as the vehicle-treated group (Fig. 7AI,III,IV). The seizure-induced prolongation of QT interval is very obvious in KA control, which was significantly blocked in PACAP(6-38) and minocycline-microinjected rats. The PR interval was significantly reduced in the $2 \mathrm{mg} / \mathrm{kg} \mathrm{KA}$-induced seizure group compared with the vehicle control group of rats (Fig. 6B). This is clearly represented in Poincare plots (Fig. 7B). In contrast to the improvements seen in the QT interval, RVLM microinjection of PACAP(6-38), minocycline, or KYNA did not prevent changes in seizure-induced shortening of PR interval (Fig. 6B). However, PACAP(6-38) (Fig. 7BIII) and minocycline (Fig. 7BIV) showed quantally dispersed PR intervals as evidenced by multiple ellipses, rather than complete R-R dispersion, and an absence of $\mathrm{P}$-waves, which is clearly not suggestive of atrial fibrillation.

\section{Discussion}

This study provides the first direct evidence that the sympathoexcitation, tachycardia, pressor responses, and proarrhythmogenic changes during seizures are driven by activation of glutamatergic receptors, which leads to increased activity of the sympathetic premotor neurons in the RVLM. The sympathoexcitatory effect does not appear due to increases or decreases in PACAP secretion, or microglial activation. However, PACAP and microglial activity in the vicinity of RVLM neurons mediate the proarrhythmogenic changes during seizures. Central autonomic nuclei are not the source of KA-induced seizures $(2 \mathrm{mg} / \mathrm{kg})$. We confirm that the induction of seizures does not cause changes in the state of microglia within the RVLM, and microglia remain in a surveillance state with no change in the number of M2 phenotypes, supporting our in vivo electrophysiology findings.

Our results strengthen the findings that seizures have a devastating effects on the cardiovascular system (Sakamoto et al., 2008; Brotherstone et al., 2010; Bhandare et al., 2015), with immediate cardiovascular effects that last for $\sim 3 \mathrm{~h}$ (Lothman et al., 1981). Importantly, these cardiovascular changes are downstream effects of seizure-induced autonomic overactivity and mediated by the action of the excitatory amino acid, L-glutamate, on sympathetic premotor neurons in the RVLM as the bilateral microinjection of ionotropic glutamate receptor antagonist KYNA completely abolished these changes. Glutamatergic synapses are important in the development of seizures, as seizure elevates the glutamate levels in the extracellular fluid of the rat hippocampus (Chapman, 1998; Faingold and Casebeer, 1999; Ueda et al., 2001; Kanamori and Ross, 2011). The RVLM contains sympathetic premotor neurons responsible for maintaining tonic excitation of sympathetic preganglionic neurons involved in cardiovascular

\section{$\leftarrow$}

(Figure legend continued.) with the microglial antagonist minocycline, prolongation of QT interval and the dysrhythmia is abolished (III, IV). Following treatment with KYNA, the HR and QT are restored to normal ( $\boldsymbol{V}$. HR-triggered ECG was drawn before and after treatment and shown in the right side corner of each box. Continuous black and dotted red lines indicate pretreatment and post-treatment ECG, respectively. $\boldsymbol{B}$, Induction of seizures with intraperitoneal KA injection shortened the PR interval (II) compared with vehicle control. RVLM microinjection of PACAP(6-38) (III), minocycline (IV), or KYNA (V) did not show changes in seizure-induced short PR interval; however, PACAP(6-38) (III) and minocycline (IV) showed more dispersed PR interval with multiple ellipses. Scale bars are in milliseconds. regulation (Guyenet, 2006; Pilowsky et al., 2009). Increased activity of sympathetic premotor RVLM neurons has significant effect on cardiac electrophysiology and is arrhythmogenic during seizures (Metcalf et al., 2009; Damasceno et al., 2013). Microinjection of L-glutamate into the RVLM causes pressor responses and sympathoexcitation that is completely blocked with KYNA (Ito and Sved, 1997; Araujo et al., 1999; Dampney et al., 2003). KYNA microinjection into RVLM on its own does not affect basal blood pressure and sympathetic activity (Guyenet et al., 1987; Kiely and Gordon, 1994; Araujo et al., 1999). Subsequently, Ito and Sved (1997) observed that, if the caudal ventrolateral medulla (inhibitory drive to the RVLM) is inhibited first, subsequent blockade of glutamate receptor in the RVLM markedly reduces blood pressure. In this paradigm, glutamatergic input to the RVLM directly excites presympathetic neurons and indirectly inhibit gamma-GABAergic inhibition of the RVLM, and the lack of change in arterial pressure with KYNA in the RVLM reflects the balance of these two actions. Miyawaki et al. (2002) also observed that, after blockade of GABAergic input within the RVLM, injection of KYNA produced inhibition of splanchnic and lumbar sympathetic nerve activity. Together, these findings illustrate that there is a tonic glutamatergic input with the existence of additional sources of neurotransmitter drive to RVLM neurons. We hypothesized that the increased concentration of glutamate in the RVLM during seizure leads to sympathoexcitation, tachycardia, and pressor responses. In turn, the responses can be antagonized by microinjection of KYNA into RVLM; indeed, our findings support this hypothesis. The findings suggest that not only sympathoexcitation but also proarrhythmogenic changes during seizures are mediated through glutamatergic receptor activation in RVLM catecholaminergic neurons. RVLM microinjection of KYNA (as well as PACAP(6-38) and minocycline) was unable to block the reduction in PR interval. In this paradigm, it is possible that the KA treatment had peripheral effects on dromotropy at the level of the AV node.

Generalized seizures in rats cause the expression of Fos, a protein marker of recently activated neurons (Minson et al., 1994), in brainstem catecholaminergic neurons in RVLM (Silveira et al., 2000). Earlier studies also suggests that $C 1$ neurons are activated following seizure (Kanter et al., 1995), findings that were supported in our previous, and current work (Bhandare et al., 2015), where KA-induced seizures in rats elicited sympathoexcitation, tachycardia, and pressor responses. Together, the findings confirm that during seizure most of the excitatory effects of glutamate in RVLM are mediated by ionotropic receptors because the broad-spectrum ionotropic glutamate receptor (NMDA, AMPA, and kainate) antagonist (KYNA) completely abolished these effects.

PACAP is a 38 amino acid pleotropic neuropeptide. The effects of PACAP are mediated via three different G-protein receptors (PAC1R, VPAC1R, and VPAC2R); all are positively coupled to adenylate cyclase. PACAP gene expression is increased in the paraventricular nucleus of the hypothalamus after KA-induced temporal lobe epilepsy in rats (Nomura et al., 2000), whereas PACAP is sympathoexcitatory (Lai et al., 1997; Farnham et al., 2008, 2012; Gaede et al., 2012), anti-inflammatory, and neuroprotective (Shioda et al., 1998) on sympathetic preganglionic neurons during seizure (Bhandare et al., 2015). Therefore, we aimed to determine whether or not PACAP also has a sympathoexcitatory or neuroprotective effect on RVLM sympathetic premotor neurons during seizures. The findings show that blockade of PACAP receptors (PAC1 and VPAC2) in the RVLM does not affect seizure-induced sympathoexcitation, tachycardia, and hypertension but does abolish prolongation of the QT 

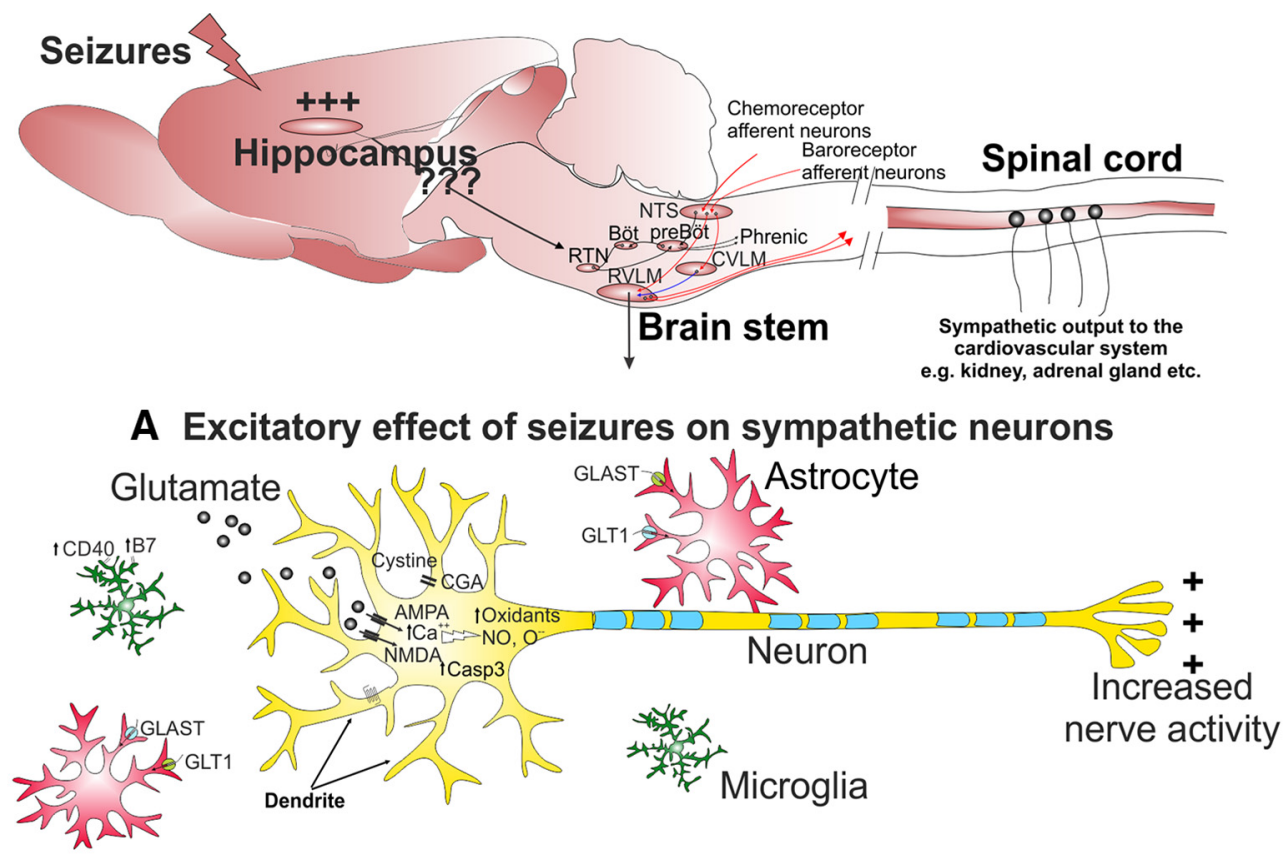

\section{B Possible effect of PACAP and microglia on sympathetic neurons during seizures}

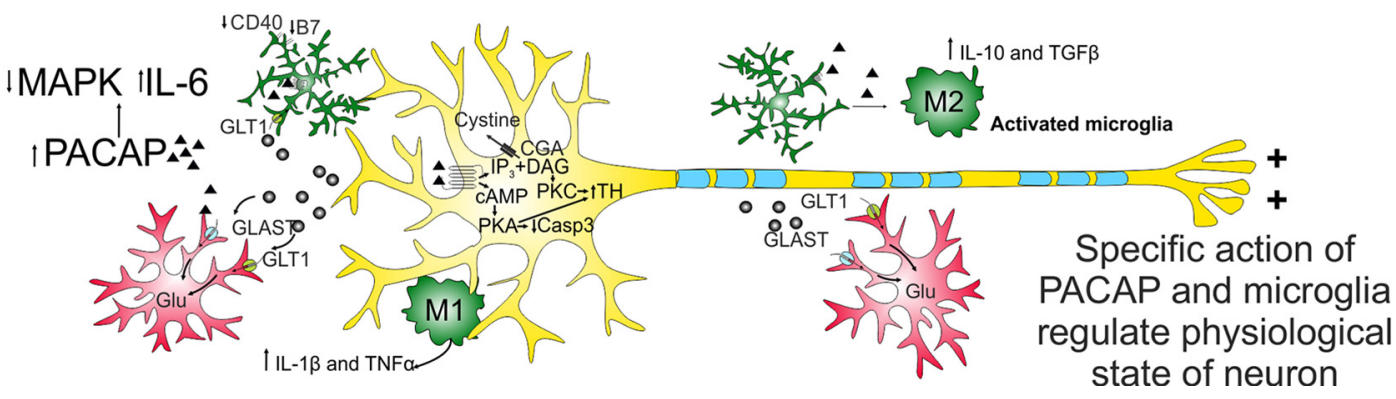

Figure 8. A proposed mechanism by which hippocampal seizures induce increased activity of sympathetic premotor neurons in the RVLM and role of glutamate, PACAP, and microglia. $A$, Seizure elevates synaptic glutamate release that can act on postsynaptic AMPA or NMDA receptors. Activation of AMPA or NMDA receptors leads to inhibition of cysteine uptake and influx of extracellular calcium, which stimulates production of oxidants, $\mathrm{NO}$ and $\mathrm{O}^{-}$. Under repetitive and extreme neuronal activation, neurotoxic effects are mediated through increased production of apoptotic factor-like caspase-3. Glutamate transporters are expressed by astrocytes and play an important role in rapid clearance of the synaptically released glutamate, whose expression is downregulated in seizure. Together, increased oxidative stress and cellular excitability cause increased activity of sympathetic premotor neurons. $\boldsymbol{B}$, Increased PACAP expression can act via cAMP-mediated PKA and/or PKC pathways and produce either excitatory effect through phosphorylation of TH at serine 40 or neuroprotective effect regulated through decreased caspase 3 , increased glial-glutamate transporters, and redirecting microglia toward anti-inflammatory M2 phenotype. In neurons, PACAP inhibits MAPK and increases IL-6 production. Microglia are activated by PACAP binding to PAC1 and VPAC1 receptors. Subsequently, microglia increase production and release of IL-10 and TGF- $\beta$ and decrease production and release of TNF- $\alpha$, as well as downregulating CD40 and B7 surface protein expression, with a neuroprotective effect. Conversely, the pro-inflammatory phenotype of activated microglia can produce IL-1 $\beta$ and TNF- $\alpha$ that may increase the sensitivity of neurons to activation.

interval. This response to PACAP(6-38) suggests that the excitatory action of PACAP (Fig. 8) on RVLM sympathetic premotor neurons mediates proarrhythmogenic changes, but not seizure-induced sympathoexcitation. Possible explanations could be that PACAP expression in the RVLM at $2 \mathrm{~h}$ after $2 \mathrm{mg} / \mathrm{kg} \mathrm{KA}$ injection may be insufficient to produce sympathoexcitation, but enough to induce proarrhythmogenic effects. This idea is supported by the findings that PACAP gene expression reaches a maximum at $12 \mathrm{~h}$ after 12 $\mathrm{mg} / \mathrm{kg}$ KA-induced seizures in the paraventricular nucleus of the hypothalamus (Nomura et al., 2000).

Microglia are the principal resident immune cells of the CNS, contributing $\sim 10 \%$ of the total brain cell population. Activated microglia respond to environmental perturbations by adopting either a "pro-inflammatory M1" or "anti-inflammatory M2" phenotype (Li et al., 2007; Lai and Todd, 2008; Pisanu et al., 2014). Seizure causes extensive microglial activation in patients (Beach et al., 1995), and in animal models (Drage et al., 2002). There is considerable controversy surrounding the pro- (Shapiro et al., 2008) or anti-inflammatory (Mirrione et al., 2010; Eyo et al., 2014) role played by microglia during seizure. Our recent findings demonstrate that microglia are protective during seizure on sympathetic preganglionic neurons within spinal cord (Bhandare et al., 2015). The findings of the current study show that blockade of microglial activation with minocycline microinjection in RVLM abolishes the prolongation of QT interval caused by KA-induced seizures but causes no change in sympathoexcitation, tachycardia, or hypertension. Our immunohistochemical analysis revealed that there are no changes in microglial morphology or phenotype in the vicinity of RVLM neurons (branch length or number of endpoint processes) or proportion of the $\mathrm{M} 2$ phenotype following induction of seizures. The increased RVLM neuronal activity may have activated microglia (which might be insufficient to differentiate with immunohistochemistry) producing an excitatory effect and contributed to the seizure-induced prolongation of QT interval (Fig. 8).

A possible mechanism to explain the increased glutamate release from presynaptic cells during seizure, and sympathoexcitation, is 
proposed in Figure 8. The oxidative stress and inflammation in RVLM during seizure (Tsai et al., 2012) could be mediated through increased glutamate levels or functional failure of glutamate transporters. Increased synthesis and release of PACAP during seizure acts via cAMP-mediated PKA and/or PKC pathways that may have either excitatory effects through phosphorylation of $\mathrm{TH}$ at serine 40 (Bobrovskaya et al., 2007) or neuroprotective effects regulated through decreased caspase 3 (Dejda et al., 2011), increased glialglutamate transporters, and redirecting microglia toward antiinflammatory M2 phenotype (Brifault et al., 2015). PACAP inhibits MAPK and increases IL-6 (Shioda et al., 1998), whereas its action on the PAC1 and VPAC1 receptors of activated microglia increase production of IL-10, TGF- $\beta$ and decrease TNF- $\alpha$ (Wada et al., 2013). Whereas polarization of activated microglia toward proinflammatory M1 phenotype increase IL- $1 \beta$ and TNF- $\alpha$. Overall, depending on the type, severity, and intensity of stimulus, selective actions of PACAP and microglia regulate the physiological state of neurons. In the current study, both PACAP and microglia may regulate excitatory effects as their antagonism results in restoration of QT prolongation.

This is the first evidence to indicate that an increase in sympathetic nerve discharge and cardiovascular dysfunction in seizure is due to activation of glutamatergic receptors within the RVLM. Second, antagonism of PACAP and microglial activity in RVLM did not abolish the seizure-induced sympathoexcitation, hypertension, and tachycardia. Interestingly, minocycline, a drug that has central bioavailability following oral administration, and PACAP antagonist, restores the proarrhythmogenic effects of seizures to normal. This is the evidence for the physiological interaction between neurons and microglia. Third, the finding that microglia are not activated, and there is no change in the proportion of M2 phenotype during seizures, is consistent with our physiological findings.

In conclusion, the implications of the current findings are that, in patients with seizure, targeting glutamatergic receptors in RVLM catecholaminergic neurons and tailoring activity of PACAP and microglia in the vicinity of sympathetic premotor neurons may have protective effects and lead to novel therapies for seizure-induced cardiovascular dysfunction and SUDEP.

\section{References}

Araujo GC, Lopes OU, Campos RR (1999) Importance of glycinergic and glutamatergic synapses within the rostral ventrolateral medulla for blood pressure regulation in conscious rats. Hypertension 34:752-755. CrossRef Medline

Bardai A, Lamberts RJ, Blom MT, Spanjaart AM, Berdowski J, van der Staal SR, Brouwer HJ, Koster RW, Sander JW, Thijs RD, Tan HL (2012) Epilepsy is a risk factor for sudden cardiac arrest in the general population. PLoS One 7:e42749. CrossRef Medline

Bazett HC (1920) An analysis of the time-relations of electrocardiograms. Heart 7:353-370.

Beach TG, Woodhurst WB, MacDonald DB, Jones MW (1995) Reactive microglia in hippocampal sclerosis associated with human temporal lobe epilepsy. Neurosci Lett 191:27-30. CrossRef Medline

Bealer SL, Little JG, Metcalf CS, Brewster AL, Anderson AE (2010) Autonomic and cellular mechanisms mediating detrimental cardiac effects of status epilepticus. Epilepsy Res 91:66-73. CrossRef Medline

Bhandare AM, Mohammed S, Pilowsky PM, Farnham MM (2015) Antagonism of PACAP or microglia function worsens the cardiovascular consequences of kainic-acid-induced seizures in rats. J Neurosci 35:2191-2199. CrossRef Medline

Blümcke I, Becker AJ, Klein C, Scheiwe C, Lie AA, Beck H, Waha A, Friedl MG, Kuhn R, Emson P, Elger C, Wiestler OD (2000) Temporal lobe epilepsy associated upregulation of metabotropic glutamate receptors: correlated changes in mGluR1 mRNA and protein expression in experimental animals and human patients. J Neuropathol Exp Neurol 59:1-10. Medline
Bobrovskaya L, Gelain DP, Gilligan C, Dickson PW, Dunkley PR (2007) PACAP stimulates the sustained phosphorylation of tyrosine hydroxylase at serine 40. Cell Signal 19:1141-1149. CrossRef Medline

Brifault C, Gras M, Liot D, May V, Vaudry D, Wurtz O (2015) Delayed pituitary adenylate cyclase-activating polypeptide delivery after brain stroke improves functional recovery by inducing M2 microglia/macrophage polarization. Stroke 46:520-528. CrossRef Medline

Brotherstone R, Blackhall B, McLellan A (2010) Lengthening of corrected QT during epileptic seizures. Epilepsia 51:221-232. CrossRef Medline

Chapman AG (1998) Glutamate receptors in epilepsy. Prog Brain Res 116: 371-383. CrossRef Medline

Damasceno DD, Savergnini SQ, Gomes ER, Guatimosim S, Ferreira AJ, Doretto MC, Almeida AP (2013) Cardiac dysfunction in rats prone to audiogenic epileptic seizures. Seizure 22:259-266. CrossRef Medline

Dampney RA, Horiuchi J, Tagawa T, Fontes MA, Potts PD, Polson JW (2003) Medullary and supramedullary mechanisms regulating sympathetic vasomotor tone. Acta Physiol Scand 177:209-218. CrossRef Medline

Dejda A, Seaborn T, Bourgault S, Touzani O, Fournier A, Vaudry H, Vaudry D (2011) PACAP and a novel stable analog protect rat brain from ischemia: insight into the mechanisms of action. Peptides 32:1207-1216. CrossRef Medline

Drage MG, Holmes GL, Seyfried TN (2002) Hippocampal neurons and glia in epileptic EL mice. J Neurocytol 31:681-692. CrossRef Medline

Eyo UB, Peng J, Swiatkowski P, Mukherjee A, Bispo A, Wu LJ (2014) Neuronal hyperactivity recruits microglial processes via neuronal NMDA receptors and microglial P2Y12 receptors after status epilepticus. J Neurosci 34:10528-10540. CrossRef Medline

Faingold C, Casebeer D (1999) Modulation of the audiogenic seizure network by noradrenergic and glutamatergic receptors of the deep layers of superior colliculus. Brain Res 821:392-399. CrossRef Medline

Farnham MMJ, Li Q, Goodchild AK, Pilowsky PM (2008) PACAP is expressed in sympathoexcitatory bulbospinal $\mathrm{C} 1$ neurons of the brain stem and increases sympathetic nerve activity in vivo. Am J Physiol Regul Integr Comp Physiol 294:1304-1311. CrossRef Medline

Farnham MM, Lung MS, Tallapragada VJ, Pilowsky PM (2012) PACAP causes PAC1/VPAC2 receptor mediated hypertension and sympathoexcitation in normal and hypertensive rats. Am J Physiol Heart Circ Physiol 303:910-917. CrossRef Medline

Gaede AH, Inglott MA, Farnham MM, Pilowsky PM (2012) Catestatin has an unexpected effect on the intrathecal actions of PACAP dramatically reducing blood pressure. Am J Physiol Regul Integr Comp Physiol 303: R719-R726. CrossRef Medline

Gurbanova AA, Aker RG, Sirvanci S, Demiralp T, Onat FY (2008) Intraamygdaloid injection of kainic acid in rats with genetic absence epilepsy: the relationship of typical absence epilepsy and temporal lobe epilepsy. J Neurosci 28:7828-7836. CrossRef Medline

Guyenet PG (2006) The sympathetic control of blood pressure. Nat Rev Neurosci 7:335-346. CrossRef Medline

Guyenet PG, Filtz TM, Donaldson SR (1987) Role of excitatory amino acids in rat vagal and sympathetic baroreflexes. Brain Res 407:272-284. CrossRef Medline

Ito S, Sved AF (1997) Tonic glutamate-mediated control of rostral ventrolateral medulla and sympathetic vasomotor tone. Am J Physiol Regul Integr Comp Physiol 273:487-494. Medline

Kanamori K, Ross BD (2011) Chronic electrographic seizure reduces glutamine and elevates glutamate in the extracellular fluid of rat brain. Brain Res 1371:180-191. CrossRef Medline

Kanter RK, Strauss JA, Sauro MD (1995) Seizure-induced c-fos expression in rat medulla oblongata is not dependent on associated elevation of blood pressure. Neurosci Lett 194:201-204. CrossRef Medline

Kiely JM, Gordon FJ (1994) Role of rostral ventrolateral medulla in centrally mediated pressor responses. Am J Physiol Heart Circ Physiol 267:H1549_ H1556. Medline

Lai AY, Todd KG (2008) Differential regulation of trophic and proinflammatory microglial effectors is dependent on severity of neuronal injury. Glia 56:259-270. CrossRef Medline

Lai CC, Wu SY, Lin HH, Dun NJ (1997) Excitatory action of pituitary adenylate cyclase activating polypeptide on rat sympathetic preganglionic neurons in vivo and in vitro. Brain Res 748:189-194. CrossRef Medline

LeBlanc BW, Zerah ML, Kadasi LM, Chai N, Saab CY (2011) Minocycline injection in the ventral posterolateral thalamus reverses microglial reac- 
tivity and thermal hyperalgesia secondary to sciatic neuropathy. Neurosci Lett 498:138-142. CrossRef Medline

Li L, Lu J, Tay SS, Moochhala SM, He BP (2007) The function of microglia, either neuroprotection or neurotoxicity, is determined by the equilibrium among factors released from activated microglia in vitro. Brain Res 1159: 8-17. CrossRef Medline

Lothman EW, Collins RC, Ferrendelli JA (1981) Kainic acid-induced limbic seizures: electrophysiologic studies. Neurology 31:806-812. CrossRef Medline

Massey CA, Sowers LP, Dlouhy BJ, Richerson GB (2014) Mechanisms of sudden unexpected death in epilepsy: the pathway to prevention. Nat Rev Neurol 10:271-282. CrossRef Medline

Meldrum BS, Akbar MT, Chapman AG (1999) Glutamate receptors and transporters in genetic and acquired models of epilepsy. Epilepsy Res 36:189-204. CrossRef Medline

Metcalf CS, Poelzing S, Little JG, Bealer SL (2009) Status epilepticus induces cardiac myofilament damage and increased susceptibility to arrhythmias in rats. Am J Physiol Heart Circ Physiol 297:H2120-H2127. CrossRef Medline

Minson JB, Llewellyn-Smith IJ, Arnolda LF, Pilowsky PM, Oliver JR, Chalmers JP (1994) Disinhibition of the rostral ventral medulla increases blood pressure and Fos expression in bulbospinal neurons. Brain Res 646:44-52. CrossRef Medline

Mirrione MM, Konomos DK, Gravanis I, Dewey SL, Aguzzi A, Heppner FL, Tsirka SE (2010) Microglial ablation and lipopolysaccharide preconditioning affects pilocarpine-induced seizures in mice. Neurobiol Dis 39: 85-97. CrossRef Medline

Miyawaki T, Goodchild AK, Pilowsky PM (2002) Evidence for a tonic GABA-ergic inhibition of excitatory respiratory-related afferents to presympathetic neurons in the rostral ventrolateral medulla. Brain Res 924: 56-62. CrossRef Medline

Nadler JV (1981) Kainic acid as a tool for the study of temporal lobe epilepsy. Life Sci 29:2031-2042. CrossRef Medline

Nei M, Ho RT, Abou-Khalil BW, Drislane FW, Liporace J, Romeo A, Sperling MR (2004) EEG and ECG in sudden unexplained death in epilepsy. Epilepsia 45:338-345. CrossRef Medline

Nomura M, Ueta Y, Hannibal J, Serino R, Yamamoto Y, Shibuya I, Matsumoto T, Yamashita H (2000) Induction of pituitary adenylate cyclaseactivating polypeptide mRNA in the medial parvocellular part of the paraventricular nucleus of rats following kainic-acid-induced seizure. Neuroendocrinology 71:318-326. CrossRef Medline

Ohtaki H, Nakamachi T, Dohi K, Aizawa Y, Takaki A, Hodoyama K, Yofu S, Hashimoto H, Shintani N, Baba A, Kopf M, Iwakura Y, Matsuda K, Arimura A, Shioda S (2006) Pituitary adenylate cyclase-activating polypeptide (PACAP) decreases ischemic neuronal cell death in association with IL-6. Proc Natl Acad Sci U S A 103:7488-7493. CrossRef Medline

Olsson T, Broberg M, Pope KJ, Wallace A, Mackenzie L, Blomstrand F, Nilsson M, Willoughby JO (2006) Cell swelling, seizures and spreading depression: an impedance study. Neuroscience 140:505-515. CrossRef Medline

Phillips JK, Goodchild AK, Dubey R, Sesiashvili E, Takeda M, Chalmers J, Pilowsky PM, Lipski J (2001) Differential expression of catecholamine biosynthetic enzymes in the rat ventrolateral medulla. J Comp Neurol 432:20-34. CrossRef Medline

Pilowsky PM, Lung MS, Spirovski D, McMullan S (2009) Differential regulation of the central neural cardiorespiratory system by metabotropic neurotransmitters. Philos Trans R Soc Lond B Biol Sci 364:2537-2552. CrossRef Medline

Pisanu A, Lecca D, Mulas G, Wardas J, Simbula G, Spiga S, Carta AR (2014) Dynamic changes in pro-and anti-inflammatory cytokines in microglia after PPAR- $\gamma$ agonist neuroprotective treatment in the MPTPp mouse model of progressive Parkinson's disease. Neurobiol Dis 71:280-291. CrossRef Medline

Ross CA, Ruggiero DA, Joh TH, Park DH, Reis DJ (1984) Rostral ventrolateral medulla: selective projections to the thoracic autonomic cell column from the region containing $\mathrm{C} 1$ adrenaline neurons. J Comp Neurol 228: 168-185. CrossRef Medline

Sakamoto K, Saito T, Orman R, Koizumi K, Lazar J, Salciccioli L, Stewart M (2008) Autonomic consequences of kainic acid-induced limbic cortical seizures in rats: peripheral autonomic nerve activity, acute cardiovascular changes, and death. Epilepsia 49:982-996. CrossRef Medline

Schreihofer AM, Guyenet PG (1997) Identification of C1 presympathetic neurons in rat rostral ventrolateral medulla by juxtacellular labeling in vivo. J Comp Neurol 387:524-536. CrossRef Medline

Shapiro LA, Wang L, Ribak CE (2008) Rapid astrocyte and microglial activation following pilocarpine-induced seizures in rats. Epilepsia 49:33-41. CrossRef Medline

Shioda S, Ozawa H, Dohi K, Mizushima H, Matsumoto K, Nakajo S, Takaki A, Zhou CJ, Nakai Y, Arimura A (1998) PACAP protects hippocampal neurons against apoptosis: involvement of JNK/SAPK signaling pathway. Ann N Y Acad Sci 865:111-117. CrossRef Medline

Silveira DC, Schachter SC, Schomer DL, Holmes GL (2000) Flurothylinduced seizures in rats activate Fos in brainstem catecholaminergic neurons. Epilepsy Res 39:1-12. CrossRef Medline

Sokal RR, Rohlf FJ (2012) Biometry, Ed 4. New York: Freeman.

Sperk G, Lassmann H, Baran H, Kish SJ, Seitelberger F, Hornykiewicz O (1983) Kainic acid induced seizures: neurochemical and histopathological changes. Neuroscience 10:1301-1315. CrossRef Medline

Surges R, Thijs RD, Tan HL, Sander JW (2009) Sudden unexpected death in epilepsy: risk factors and potential pathomechanisms. Nat Rev Neurol 5:492-504. CrossRef Medline

Sved AF, Ito S, Yajima Y (2002) Role of excitatory amino acid inputs to the rostral ventrolateral medulla in cardiovascular regulation. Clin Exp Pharmacol Physiol 29:503-506. CrossRef Medline

Tsai CY, Chan JY, Hsu KS, Chang AY, Chan SH (2012) Brain-derived neurotrophic factor ameliorates brain stem cardiovascular dysregulation during experimental temporal lobe status epilepticus. PLoS One 7:e33527. CrossRef Medline

Ueda Y, Doi T, Tokumaru J, Yokoyama H, Nakajima A, Mitsuyama Y, OhyaNishiguchi H, Kamada H, Willmore LJ (2001) Collapse of extracellular glutamate regulation during epileptogenesis: down-regulation and functional failure of glutamate transporter function in rats with chronic seizures induced by kainic acid. J Neurochem 76:892-900. CrossRef Medline

Vinet J, van Weering HRJ, Heinrich A, Kälin RE, Wegner A, Brouwer N, Heppner FL, van Rooijen N, Boddeke HWGM, Biber K (2012) Neuroprotective function for ramified microglia in hippocampal excitotoxicity. J Neuroinflamm 9:27. CrossRef Medline

Wada Y, Nakamachi T, Endo K, Seki T, Ohtaki H, Tsuchikawa D, Hori M, Tsuchida M, Yoshikawa A, Matkovits A, Kagami N, Imai N, Fujisaka S, Usui I, Tobe K, Koide R, Takahashi H, Shioda S (2013) PACAP attenuates NMDA-induced retinal damage in association with modulation of the microglia/macrophage status into an acquired deactivation subtype. J Mol Neurosci 51:493-502. CrossRef Medline 